\title{
Effect of pneumatic shot peening on the high and low cycle combined fatigue life of K403 turbine blades
}

\author{
Xin Ding ${ }^{1}$, Dawei Huang ${ }^{1}$, Xiaojun Yan ${ }^{1}$, Xiaoyong Zhang ${ }^{1}$, Mingjing Qi ${ }^{1}$, and Zhiwei Liu ${ }^{1}$ \\ ${ }^{1}$ Beihang University
}

July 29, 2020

\begin{abstract}
The effect of pneumatic shot peening (PSP) on the fatigue properties of K403 turbine blades has been investigated under the high and low cycle combined fatigue $(\mathrm{CCF})$ load with two types of blades: untreated blades and PSP treated blades. It is found that there is a threshold vibration stress which should be 194MPa. The PSP has a positive effect on the CCF life of blades mainly due to the compressive residual stress resulting in the reduction of the number of crack sources and propagation rate when vibration stresses are below the threshold vibration stress. However, the PSP treatment has no or negative effect when vibration stresses are above the threshold value. The compressive residual stress is released along with the microstructure changes of K403. Meanwhile, the microstructure changes, reflected in the precipitation of the lamellar MC carbides and $\sigma$ phases, can accelerate the process of crack initiation and propagation.
\end{abstract}

\section{KEY WORDS}

CCF test, PSP treatment, residual stress, turbine blades, threshold vibration stress

\section{1 | INTRODUCTION}

The turbine blades are the indispensable components of aero-engines, which usually suffer from various loads (such as thermal load, centrifugal load, aerodynamic load and vibration load[1-4]. The effect of thermal load and centrifugal load is considered to be the low cycle fatigue (LCF) due to the large stress during the flight cycles. Besides, the blades may suffer from the aerodynamic load and vibration load causing the supernumerary stress which is recognized to be the high cycle fatigue (HCF)[5]. During the actual operation, turbine blades are subject to the combined HCF and LCF loads simultaneously so that the fatigue damage of the turbine blades increases largely [6-9]. Therefore, it is necessary to investigate how to extend the CCF life of the turbine blades.

The PSP is an effective surface treatment method to improve the surface properties of metal. High-speed particles are sprayed onto the metal surface in order to produce the plastic deformation and compressive residual stress which can improve the fatigue strength and life of metal. Currently, PSP treatment has been used in the manufacture of fans, turbine blades and discs to improve the fatigue life [10]. However, the effect of PSP treatment on the CCF life of turbine blades has rarely been reported before.

Large number of researches about the effect of PSP on the fatigue life of the metal are carried out [11-23]. Gao et al. [11] investigate the effect of PSP on the small crack growth rate and fatigue life of 7475-T7351 aluminum alloy. The results indicate that fatigue crack growth rate greatly decreases after the PSP treatment. And the fatigue life extension introduced by PSP could be attributed to the beneficial compressive residual stress in the surface layer. Takeda et al. [12] study the influence of the PSP treatment on the fatigue life of TiNi shape memory alloy. They find that the fatigue life increases significantly due to the residual compressive 
stress. Benedetti et al. [13] study the effect of PSP on the high and very-high cycle plain fatigue resistance of the Al-7075-T651 aluminum alloy. It is found that the PSP treatment could retard the initiation and subsequent the propagation of cracks.

At present, the effect of PSP on material fatigue properties is usually studied with the smooth specimens. However, the differences between the full-scale turbine blades and smooth specimens, such as the geometry structure, heat treatment, manufacturing process and microstructure, may cause the discrepancy between their mechanical performance and life distribution [16]. And these factors may further affect the improvement of PSP on the fatigue performance. Therefore, it is necessary to investigate the effect of PSP on the full-scale turbine blades.

Accordingly, this investigation aims to study the effect of PSP treatment on the CCF behavior of fullscale turbine blades. One CCF test system is designed, which can apply the high and low cycle loads simultaneously without interfering with each other. And the CCF tests based on untreated and PSP treated turbine blades are carried out to study the effect of PSP treatment on the CCF life of the full-scale turbine blades.

\section{2 | EXPERIMENTS}

\subsection{Material and specimens}

Two groups of turbine blades are tested in the study. One group is treated by the PSP treatment, and the other group of turbine blades that are not treated by PSP is the same as those used in the actual outer field. The blades are cast with the K403 nickel-base superalloy. The heat treatment of these blades is carried out at $1210^{\circ} \mathrm{C}$ in a pit-type gas carburizing furnace for $4 \mathrm{~h}$. Then, the blades are cooled to room temperature in air.

The chemical composition of K403 is shown in Figure 1(a). The microstructure is observed as the $\gamma$ phase, $\gamma^{\prime}$ phase and $\left(\gamma+\gamma^{\prime}\right)$ eutectic phase and MC carbides (Figure 1(b)). The $\gamma$ solid solution is the matrix phase, and the $\gamma^{\prime}$ phase is the main strengthening phase. The $\gamma^{\prime}$ phase whose mass fraction is $57 \%$ has a surface-centered cubic structure. The volume fraction of $\left(\gamma+\gamma^{\prime}\right)$ eutectic is $2 \%$.

\section{2 | Critical position}

Standard specimen (e.g. round rod test piece) usually has a gauge section where the failure occurs. In contrast, the geometry structure and stress distribution of turbine blades are complicated. Before the CCF tests, the critical position under CCF load must be confirmed. The determination of the critical position is based on the combination of the finite element calculation and external field failure. The stress distribution of the turbine blades under the real flight condition is shown in Figure 2(a). It indicates that the maximum stress is located at the upper part of the first stage serration. Besides, Figure 2(b) shows that the blades break at the upper part of the first stage serration in the actual outer field. Therefore, the critical position should be the upper part of the first serration on the leaf side.

\section{3 | PSP treatment}

One PSP treatment system in Figure 3(a) is established for turbine blades. And the detailed parameters of the PSP treatment are listed in Figure 3(b). The PSP treatment is conducted by two bucket-type enclosed pneumatic machines and one air compressor, using the cast steel particles with hardness from 45 to 48 HRC. These steel particles are sprayed onto the serrations of turbine blades to produce the residual compressive stress.

Before the CCF tests, the hardness and surfaces in the PSP treatment area of the untreated and PSP treated blade are investigated. The surfaces of turbine blades are observed by the scan electric microscope (SEM). As shown in Figure 4(a), there are lots of machining traces left on the surfaces of untreated blades. However, the machining traces are eliminated and many surface pits form after the PSP treatment due to the shooting of steel particles (Figure 4(b)). 
The surface hardness $\left(\mathrm{HV}_{0.1}\right)$ of the critical location is examined by the Vickers hardness tester (Figure $4(\mathrm{c})$ ). The result indicates that the hardness is greatly improved by the PSP treatment within the depth of 180um from the top surface. Besides, Figure 4(d) shows the residual stress at the critical location examined by the X-ray. After the PSP treatment, there is a high-level of compressive residual stress and the maximum residual stress of which is about 60um deep from the top surface. According to the curves in Figure 4(c) and (d), the PSP treatment effect depth is about 180-190um.

The microstructure of K403 superalloy at the critical position before the CCF tests is shown in Figure 4(e) and (f). The obvious plastic deformation can be observed on the surface after the PSP treatment. Moreover, a number of carbides with cracks form near the surface. It indicates that the plastic deformation and large stress resulting from the PSP treatment may cause the fragmentation of carbides due to the brittleness.

\section{4 | Test conditions and CCF test system}

The conditions of CCF tests are listed in and the test load spectrum is shown in Figure 5(a). Since it is difficult to determine the value of the high-cycle loads, CCF tests are carried out at several vibration amplitudes in this study. According to the experimental data under different vibration amplitudes, the $\sigma_{\mathrm{H}^{-}}$ $\mathrm{N}$ curve (in which $\sigma_{\mathrm{H}}$ represents the vibration stress and $\mathrm{N}$ represents the CCF life expressed by high-cycle fatigue cycles) can be obtained. The last column of Table 1 shows the number of specimens under different load conditions. 3 or 4 blades are tested to consider the dispersion at some specific vibration amplitudes. All the blades are tested until fracture.

One CCF test system shown in Figure 5(b) is established. It mainly consists of the servo-electric fatigue tester, clamp, electromagnetic induction heating equipment and electromagnetic vibration exciter. Figure 5(c) and (d) show the clamp which can apply the LCF load and HCF load to the blades simultaneously without interfering with each other. The low-cycle load is not applied to the blades directly. Instead, it is applied to the top of the outer clamp and transfers to the blades through the inner clamp along the load path (the red arrow in Figure 5(c)). The electromagnetic vibration exciter, which generates the high-cycle vibration load, is connected to the inner clamp. There are two bearings between the outer clamp and inner clamp in order to reduce friction and ensure that the inner clamp can vibrate freely.

In addition, it is significant to ensure the relationship between the vibration stresses of the critical position and vibration amplitudes. This aim is to control the vibration stresses of the critical position by controlling the vibration amplitudes during the CCF tests. The FE method is applied to calculate the vibration stress distribution of the critical position at different vibration amplitudes. Figure 6 indicates that there is a linear relationship between the vibration stresses of the critical position and vibration amplitudes.

\section{3 | EXPERIMENTAL RESULTS}

\section{1 | CCF life}

The valid CCF life results are listed in Figure 7(a). Among them, thirteen CCF life results come from the untreated blades and the other nine results come from the PSP treated blades. According to these test data, the $\sigma_{\mathrm{H}}-\mathrm{N}$ curves of untreated and PSP treated blades are shown in Figure $7(\mathrm{~b})$. There is a linear relationship between CCF life and vibration stress amplitudes. Furthermore, the least squares method is used to fit experimental data to get the fitting equations listed in Figure 7(b). It indicates that there is one threshold vibration stress with the value of 194.0MPa. When the vibration stresses are lower than the threshold value, the PSP treatment has a positive effect on the CCF life of blades. In contrast, the PSP treatment has a negative effect on the CCF life while the vibration stresses are above the threshold value.

\subsection{Crack initiation and propagation}

Figure 8 shows the partially broken blades. And the crack sources on the fracture surface of the broken turbine blades are observed by the optical microscope (OM) (Figure 9(a)). The number of crack sources of the PSP treated blades (C2, C5) is less than that of the untreated (B2, B4) blades. Therefore, it is 
determined that the PSP treatment can significantly reduce the number of crack sources while the vibration stresses are below the threshold vibration stress. In contrast, the number of crack sources of PSP treated blade (C9) is more than that of untreated blade (B9) while the vibration stress is above the threshold value. This indicates that the number of crack sources cannot be reduced by the PSP treatment while the vibration stresses are above the threshold vibration stress.

The crack sources of untreated (B2, B9) and PSP treated (C2, C9) blades are shown in Figure 9 (b)-(e). The cracks of B2, B9 and C9 blades initiate from the top surface. In contrast, the crack initiation position of the $\mathrm{C} 2$ blade is the matrix near the top surface. Especially for the C9 blade, the lamellate structure can be observed near the crack source on the fracture surface.

Figure 10 shows the fatigue striations of the crack propagation section on the fracture surface of untreated $(\mathrm{B} 2, \mathrm{~B} 9)$ and PSP treated $(\mathrm{C} 2, \mathrm{C} 9)$ blades. All the selected observation areas are 100um away from the crack source at the critical position. According to the measurement results of fatigue striations marked in Figure 10 , the width of fatigue striations for the PSP treated blade $(\mathrm{C} 2)$ is smaller than that of the untreated blade (B2). This indicates that the PSP treatment is able to reduce the growth rate of the cracks due to the compressive residual stress while the vibration stresses are below the threshold vibration stress, for which it is beneficial to improve the fatigue property of superalloy. However, the crack growth rate of B9 blade is greatly accelerated by the large vibration stress compared with that of B2 blade, which demonstrates that CCF damage significantly increases. Especially for the C9 blade, the fracture surface near the crack source is characterized by the small dimples accompanied with the lamellar structure.

\section{4 | MICROSTRUCTURE FEATURES}

\section{1 | Results of untreated blades}

The longitudinal section diagrams of untreated blades are shown in Figure 11. In Figure 11(a) and (c), it is found that the cracks initiate near the bulk carbides on the top surface. And the cracks are easy to propagate along the grain boundaries. In fact, the carbides precipitate from the matrix, connect with each other and rupture due to the interaction of the high temperature and CCF load. This may make the grain boundaries become the weaken locations. And the maximum total stress is on the top surface. Therefore, the cracks initiate from the carbides on the top surface and propagate along the grain boundaries (Figure $11(\mathrm{~b})$ and $(\mathrm{d}))$.

\section{2 $\mid$ Results of PSP treated blades when the vibration stresses are below the threshold value}

\subsubsection{Phase precipitations and transitions}

Figure 12 shows the SEM morphology and EDS analyze results of the PSP treated blades while the vibration stress is below the threshold value. The major contents of different phases based on the EDS spot scanning are listed in Figure 12(d). According to the elemental analysis results, the phases labelled (a) and (b) are the $\gamma$ ' phase and $\gamma$ phase. The phase labelled (c), which is rich in $\mathrm{C}, \mathrm{Ti}, \mathrm{W}$ and Co elements, is considered to be the bulk MC carbides. Furthermore, the phase labelled (d) that contains the insoluble $\mathrm{W}$ element and is short of $\mathrm{Ti}$ and $\mathrm{Cr}$ elements is supposed to be the $\mathrm{M}_{6} \mathrm{C}$ carbides. Besides, the phase labelled (e) should be the $\mathrm{M}_{23} \mathrm{C}_{6}$ carbides which mainly consist of $\mathrm{C}$ and $\mathrm{Cr}$ elements [24].

In fact, the $\mathrm{MC}$ carbides may degenerate into the $\mathrm{M}_{23} \mathrm{C}_{6}$ or $\mathrm{M}_{6} \mathrm{C}$ carbides during the CCF tests in the form of the following equations:

$$
\mathrm{MC}+\gamma-\mathrm{M}_{23} \mathrm{C}_{6}+\gamma^{\prime}(1)
$$

or

$\mathrm{MC}+\gamma-\mathrm{M}_{6} \mathrm{C}+\gamma^{\prime}(2)$

Especially, the formation of the $\mathrm{M}_{23} \mathrm{C}_{6}$ carbides results in the depletion of the Cr element in the $\gamma$ phase, which further leads to the generation of cationic vacancies. These cationic vacancies may enlarge, gather, connect with each other and develop into the micro-holes [25]. 


\subsection{2 | Micro-cracks and fracture}

The longitudinal section diagrams of PSP treated blades are shown in Figure 12(e) and (f), when the blades are tested under the vibration stresses below the threshold value. The bulk carbides form near the grain boundaries and on the fracture surface, which are easy to rupture to result in micro-cracks under the CCF load. Therefore, the grain boundaries become weaken during the CCF tests. In Figure 12(f), the micromorphology at the failure location indicates that the blade has failed along the grain boundaries. Actually, under the interaction of the residual stress and CCF load, the maximum stress is in the matrix near the top surface. The micro-cracks initiate from the bulk carbides inside the matrix, propagate along the grain boundaries and finally develop into visible cracks [20,26-27].

4.3 Results of PSP treated blades when the vibration stresses are above the threshold value

\subsubsection{Phase precipitations and transitions}

The SEM morphology and EDS analyze results of the PSP treated blades at the fracture location are shown in Figure 13. The element compositions of different phases observed from the EDS spot scanning are listed in Figure 13(d). According to the previous investigations, the phases labelled (a) and (b) are the $\gamma$ phase and $\gamma^{\prime}$ phase, respectively. Besides, the long needle-like phases labelled (c), which are rich in the Ti, Mo, W and $\mathrm{C}$ elements, are observed on the fracture. They should be the proeutectoid MC carbides precipitating from the matrix. The long needle-like MC carbides are prone to rupture owing to the brittleness under the CCF load. Based on the results mentioned in section 4.2, the phases labelled (d) and (e) are the $\mathrm{M}_{23} \mathrm{C}_{6}$ and $\mathrm{M}_{6} \mathrm{C}$ carbides, respectively. Furthermore, the needle-like phases labelled (f), which abound in the Ni, Cr, Mo and $\mathrm{W}$ elements, are confirmed to be the $\sigma$ phases. Actually, the precipitation of carbides resulting in the depletion of $\mathrm{C}$ elements and enrichment of insoluble $\mathrm{W}$ and Mo elements causes the formation of the $\sigma$ phases [28-29].

\subsection{2 | Micro-cracks and fracture}

The longitudinal section of the PSP treated blades is observed based on SEM while vibration stresses of CCF tests are above the threshold value (Figure 13(e) and (f)). It can be observed that there are long needle-like MC carbides and $\sigma$ phases. Besides, the micro-holes appear near the carbides, $\sigma$ phases and grain boundaries. And the MC carbides rupture to result in the initiation of micro-cracks owing to brittleness. The micro-cracks and micro-holes may interact, grow and further propagate into the visible cracks. According to the previous researches, the long needle-like MC carbides are the weaken locations and harmful to the strength and plasticity of alloys. Thus, the cracks easily propagate along long needle-like MC phases so that there are wedge-shaped notches on the fracture surface (Figure 13 (f)) [30-31].

\section{5 | DISCUSSION}

In order to understand the reason why PSP treatment has the positive or negative effect on the CCF life of blades while the vibration stresses are below or above the threshold value. The detailed damage evolution mechanisms of untreated and PSP treated blades under different vibration stresses are discussed in this section.

\section{1 | Damage evolution mechanisms of the untreated blades}

Figure 14 shows the damage evolution mechanisms of untreated blades during CCF tests under different vibration stresses. The initial state of the blades is shown in Figure 14 (a). The surfaces of turbine blades are directly exposed to air and oxidized during the CCF tests. The bulk carbides precipitate near grain boundaries.

During the CCF tests, the maximum stress appears on the surface and causes the elastic or plastic strain. The high-level stress may cause the dislocations and migration of grain boundaries. The carbides that precipitate from the matrix and aggregate along the grain boundaries can hinder the increase of dislocation. Due to the high-level stress, the large bulk carbides may rupture accompanied by the initiation of micro-cracks (Figure $14(\mathrm{~b}))$. 
Before the failure, with the cyclic loading and damage accumulation, micro-cracks initiate on the top surface, gradually gather and extend into visible cracks. The visible cracks propagate along grain boundaries that are full of carbides. (Figure 14 (c)).

\section{2 | Damage evolution mechanisms of the PSP treated blades}

\subsection{1 | Vibration stresses below the threshold value}

As for the PSP treated blades before CCF tests, the PSP treatment will cause the plastic deformation and a high-level of residual stress. The maximum of the residual stress is located in the matrix near the top surface. Therefore, the bulk carbides near the surface may rupture, which will lead to the initiations of micro-cracks (Figure $14(\mathrm{~d})$ ).

During the CCF tests, due to the interaction of the residual stress and CCF load, the maximum total stress appears in the matrix near the surface. The micro-cracks are prone to initiate at the ruptured carbides and propagate along grain boundaries. As the CCF tests continue, the bulk $\mathrm{M}_{23} \mathrm{C}_{6}$ and $\mathrm{M}_{6} \mathrm{C}$ carbides form around the MC carbides (Figure 14 (e)).

Before the failure, the micro-cracks extend into visible cracks in the matrix near the top surface. However, thanks to the high-level compressive residual stress, the growth rate of cracks can be greatly reduced, which is difficult for micro-cracks to grow into the matrix. Therefore, CCF life has been extended overall compared with the untreated blades under the same CCF load (Figure 14 (f)).

\subsection{2 | Vibration stresses above the threshold value}

Before CCF tests, the states of the blades are the same as those of the blades mentioned in Section 5.2.1 (Figure $14(\mathrm{~g})$ ).

During the CCF tests, the microstructure of blades changes differently. According to the threshold vibration stress (194.0MPa), the relationship between the threshold vibration stress and yield stress of K403 at 540 is compared (Table 2). It reveals that the total stress (the sum of the half of threshold vibration stress and static stress) is above the yield stress $\left(\sigma^{\mathrm{b}}{ }_{0.2}\right)$. According to the researches of Taira.S et al. [32] and Wick.A et al.[33], the significant relaxation of the compressive residual stress occurs when the total stress is above the yield stress. Thus, the compressive residual stress is gradually released as the CCF tests are conducted [34]. This indicates that the PSP treatment has no positive effect when the total stress is close to or above the yield stress (Figure $14(\mathrm{~h})$ ).

Furthermore, the material plastic flow stress is achieved so that the dislocations, stacking faults and microholes generate. This provides favorable conditions for the carbon atom diffusion and nucleation of carbides [35]. Apart from the formation of bulk $\mathrm{M}_{23} \mathrm{C}_{6}$ and $\mathrm{M}_{6} \mathrm{C}$ carbides, a kind of long needle-like $\mathrm{MC}$ carbides appears in the grains accompanied by the precipitation of needle-like $\sigma$ phases. The damage evolution has the following features:

- Firstly, in the initial several CCF cycles, the residual stress has not been fully released. The total stress is very close to or above the yield stress, which facilitates the precipitation of MC carbides and $\sigma$ phases. The long needle-like $\mathrm{MC}$ carbides and $\sigma$ phases are sensitive to the high-level stress. Therefore, the MC carbides rich in insoluble $\mathrm{W}$ and Mo elements can be easily ruptured to produce the micro-cracks due to the brittleness.

- Secondly, the precipitation of $\sigma$ phases rich in $\mathrm{Cr}, \mathrm{Ni}, \mathrm{W}$ and Mo elements leads to the depletion of these elements in the matrix, which weakens the solid solution strengthening effect of $\gamma$ ' phases. Besides, the cationic vacancies resulting from the depletion of $\mathrm{Cr}$ and $\mathrm{Ni}$ elements may increase, grow and gather with each other to develop into holes. These holes cause stress concentration so as to further promote the micro-cracks to propagate [36].

- Lastly, the long needle-like MC carbides, which pass through the $\gamma$ phases, are actually lamellar. The micro-cracks are prone to initiate and propagate along with the interfaces between $\gamma$ phases and MC phases, which greatly reduces the strength and plasticity of superalloy. 
Owing to the above three reasons, the initiation and propagation process of cracks are accelerated by the precipitation of lamellar MC carbides and $\sigma$ phases [37].

Before the failure, the residual stress is fully released and the maximum stress appears on the top surface. Besides, the precipitation of the lamellar MC carbides and $\sigma$ phases weakens the mechanical property of the superalloy. Therefore, the cracks initiate on the top surface and rapidly propagate along MC carbides. Therefore, the CCF life of the PSP treated blades decreases compared with that of the untreated blades ( Figure 14 (i)).

\section{6 | CONCLUSION}

The CCF test system, which can apply the high and low cycle loads simultaneously without interfering each other, is designed to study the effect of PSP treatment on the CCF life of turbine blades. The untreated and PSP treated full-scale turbine blades are tested. The results are summarized as following:

1. According to the $\sigma_{\mathrm{H}}-\mathrm{N}$ curves, the threshold vibration stress is determined to be 194.0MPa. The PSP treatment has the positive effect on the CCF life of turbine blades, only when the vibration stress is below the threshold vibration stress. While the vibration stress is above the threshold value, the PSP treatment has no or the negative effect on the CCF life.

2. The PSP treatment results in the compressive residual stress in the treated area. When the vibration stresses are below the threshold vibration stress, the number of crack sources and crack growth rate decreases due to the compressive residual stress.

3. The compressive residual stress is found to be released along with the microstructure change of K403 when the vibration stresses are above the threshold value. The lamellar MC carbides and $\sigma$ phases precipitate from the matrix. These microstructure changes accelerate both the initiation and propagation process of cracks. Therefore, the CCF life of the PSP treated blades reduces compared with that of the untreated blades.

\section{ACKNOWLEDGEMENT}

This study is supported by National Science and Technology Major Project (2017-IV-0012-0049) and the National Natural Science Foundation of China (Grant No.51805017).

\section{CONFLICT OF INTEREST}

We declare that we have no financial and personal relationships with other people or organizations that can inappropriately influence our work, there is no professional or other personal interest of any nature or kind in any product, service and/or company that could be construed as influencing the position presented in, or the review of the manuscript.

\section{AUTHOR CONTRIBUTIONS}

Design of CCF test system : Ding X, Huang DW and Yan XJ.Drafting of the manuscript: Ding X. Critical revision of the manuscript: Huang DW and Yan XJ. Statistical analysis: Zhang XY. CCF tests execution: Ding X, Qi MJ and Liu ZW.

\section{ORCID}

Dawei Huang

http://orcid.org/0000-0003-3865-3501

\section{REFERENCE}

1. Chen C, Zhang XY, Yan XJ, Ren J, Huang DW, Qi MJ. Effect of laser shock peening on combined low- and high-cycle fatigue life of casting and forging turbine blades. J. Iron and Steel Res. Int.2018;25(1):108-119.

2. Oakley SY, Nowell D. Prediction of the combined high- and low-cycle fatigue performance of gas turbine blades after foreign object damage.Int $J$ Fatigue . 2007;29(1):69-80. 
3. Schweizer C, Seifert T, Nieweg B,Von Hartrott P, Riedel H. Mechanisms and modelling of fatigue crack growth under combined low and high cycle fatigue loading. Int J Fatigue . 2011;33:194-202.

4. Han L, Huang DW, Yan XJ, Zhang XY, Gui M, Tao M, et al. Effects of aluminizing and combined strengthening on the fatigue property of K403 superalloy component under combined high and low cycle loading.Int J Fatigue . 2019;125:491-504.

5. Byrne J, Hall RF, Powell BE. Influence of LCF overloads on combined HCF/LCF crack growth. Int J Fatigue . 2003;25(9-11):827-834.

6. Hou NX, Wen ZX, Yu QM, Yue ZF. Application of a combined high and low cycle fatigue life model on life prediction of SC blade. Int J Fatigue . 2009;31(4):616-619.

7. Hu DY, Meng FC, Liu HW, Song J, Wang RQ. Experimental investigation of fatigue crack growth behavior of GH2036 under combined high and low cycle fatigue. Int J Fatigue . 2016;85:1-10.

8. Yan XJ, Qi MJ, Deng Y, Chen X, Sun RJ, Lin LS, et al. Investigation on Material's Fatigue Property Variation Among Different Regions of Directional Solidification Turbine Blades-Part II: Fatigue Tests on Bladelike Specimens. J Eng Gas Turb Power 2014;136(10).

9. Yin F, Rakita M, Hu S, Han QY. Overview of ultrasonic shot peening.Surf Eng . 2017;33(9):651-666.

10. Mccluing RC. A literature survey on the stability and significance of residual stresses during fatigue. Fatigue Fract Eng Struct.2007;30:173-205.

11. Gao YK, Wu XR. Experimental investigation and fatigue life prediction for 7475-T7351 aluminum alloy with and without shot peening-induced residual stresses. Acta Mater. 2011;59(9):3737-3747.

12. Takeda K, Matsui R, Tobushi H, Homma S, Hattori K. Enhancement of Fatigue Life in TiNi Shape Memory Alloy by Ultrasonic Shot Peening. Mater Trans.2015;56(4):513-518.

13. Benedetti M, Fontanari V, Bandini M, Savio E. High- and very high-cycle plain fatigue resistance of shot peened high-strength aluminum alloys: The role of surface morphology. Int J Fatigue. 2015;70:451-462.

14. Černý I, Sís J, Mikulová D. Short fatigue crack growth in an aircraft Al-alloy of a 7075 type after shot peening. Surf Coat Tech.2014;243:20-27.

15. González J, Bagherifard S, Guagliano M, Pariente IF. Influence of different shot peening treatments on surface state and fatigue behaviour of Al 6063 alloy. Eng Fract Mech. 2017;185:72-81.

16. Yan XJ, Chen X, Sun RJ, Deng Y, Lin LS, Nie JX. Investigation on Material's Fatigue Property Variation Among Different Regions of Directional Solidification Turbine Blades - Part I: Fatigue Tests on Full Scale Blades. J Eng Gas Turb Power. 2014;136(10).

17. He XF, Sui FC, Zhai B, Liu WT. Probabilistic and testing analysis for the variability of load spectrum damage in a fleet. Eng Fail Anal. 2013;33:419-429.

18. Liu JX, Pang M. Fatigue life prediction of shot-peened steel.Int J Fatigue. 2012;43:134-141.

19. Luong H, Hill MR. The effects of laser peening and shot peening on high cycle fatigue in 7050-T7451 aluminum alloy. Mater. Sci. Eng, A. 2010;527(3):699-707.

20. Wang C, Shen XJ, An ZB, Zhou LC, Chai Y. Effects of laser shock processing on microstructure and mechanical properties of K403 nickel-alloy. Mater Design. 2016;89:582-588.

21. Oguri K. Fatigue life enhancement of aluminum alloy for aircraft by Fine Particle Shot Peening (FPSP). J Mater Process Technol.2011;211(8):1395-1399.

22. Pariente IF, Guagliano M. Influence of Shot Peening Process on Contact Fatigue Behavior of Gears. Mater Manuf Process.2009;24(12):1436-1441.

23. Mikova K, Bagherifard S, Bokuvka O, G.ualiano M, Trsko L. Fatigue behavior of X70 microalloyed steel after severe shot peening. Int J Fatigue .2013;55:33-42.

24. Deodeshmukh VP, Srivastava SK. Effects of short- and long-term thermal exposures on the stability of a Ni-Co-Cr-Si alloy. Mater Design. 2010;31(5):2501-2509.

25. Jiang WH, Yao XD, Guan HR, Hu ZQ. Mechanism of secondary $\mathrm{M}_{23} \mathrm{C}_{6}$ precipitation around $\mathrm{MC}$ in a cobalt-base superalloy. Acta Metall Sci. 1999;12(2):155-159.

26. Pujada BR, Tichelaar FD, Janssen GCAM.Stress in tungsten carbide-diamond like carbon multilayer coatings. Appl Phys Lett . 2007;021913:90-93.

27. Shabrov MN, Sylven E, Kim S, Sherman DH, Chuzhoy L, Briant CL,et al. Void Nucleation by inclusion cracking. Metall Mater Trans A.2004;35: 1745-1755. 
28. Du BN, Yang JX, Cui CY, Sun XF. Effects of grain refinement on the microstructure and tensile behavior of K417G superalloy. Mater Sci Eng A-Struct. 2015;623:59-67.

29. Liu J, Yang H, Sun ZC, Tang WT. Effect of $950{ }^{\circ} \mathrm{C}$ thermal exposure on microstructures and properties of Ni-based K403 alloys. Rare Metal Mater Eng. 2013;42:1123-1126.

30. Acharya A, Fuchs GE. The effect of long-term thermal exposures on the microstructure and properties of CMSX-10 single crystal Ni-base superalloys. Mater Sci Eng A-Struct. 2004;381:143-153.

31. Benedetti M, Fontanari V, Allahkarami M, Hanan JC. Notch Fatigue Behaviour of Shot Peened HighStrength Aluminium Alloys: Role of the Residual Stress Field Ahead of the Notch Root. Expt Appl Mech . 2015;6:113-121.

32. Taira S, Murakami Y. On the changes in residual stresses due to repeated stressing. In: Proceedings of the 3rd Japan Congress on Testing Materials, Kyoto, Japan, 1960.

33. Wick A, Schulze V, Vohringer O. Effects of warm peening on fatigue life and relaxation behaviour of residual stresses in AISI 4140 steel. Mater Sci Eng A-Struct.2000;293:191-197.

34. McClung RC. A literature survey on the stability and significance of residual stresses during fatigue.Fatigue Fract Eng M. 2007;30(3):173-205.

35. Gui WM, Zhang HY, Yang M, Jin T, Sun XF, Zheng Q. Influence of type and morphology of carbides on stress-rupture behavior of a cast cobalt-base superalloy. J Alloy Compd . 2017;728:145-151

36. Liu LR, Jin T, Zhao NR, Wang ZH, Sun XF, Guan HR, et al. Microstructural evolution of a single crystal nickel-base superalloy during thermal exposure. Mater. Lett.2003;57:4540-4546.

37. Yang JX, Zheng Q, Sun XF, Guan HR, Hu ZQ. Topologically close-packed phase precipitation in a nickel-base superalloy during thermal exposure. Mater Sci Eng A-Struct.2007;456:100-108.

\section{Hosted file}

Submit-Table.docx available at https://authorea.com/users/347255/articles/473011-effect-ofpneumatic-shot-peening-on-the-high-and-low-cycle-combined-fatigue-life-of-k403-turbineblades

\section{Hosted file}

Submit-Figure.docx available at https://authorea.com/users/347255/articles/473011-effect-ofpneumatic-shot-peening-on-the-high-and-low-cycle-combined-fatigue-life-of-k403-turbineblades 